\title{
Influência alelopática de Phytolacca dioica L. na germinação e crescimento inicial de tomate e picão-preto
}

\author{
Junior Borella ${ }^{1 *}$ \\ Lindamir Hernandez Pastorini ${ }^{2}$ \\ Universidade Regional Integrada do Alto Uruguai e das Missões \\ Departamento de Ciências Biológicas, CEP 98400-000, Frederico Westphalen - RS, Brasil \\ *Autor para correspondência \\ jr.borella@hotmail.com
}

Submetido em 11/11/2008

Aceito para publicação em 06/03/2009

\section{Resumo}

Alelopatia se refere à capacidade que determinada planta tem de interferir no metabolismo de outra, por meio de compostos químicos liberados no meio. O objetivo deste trabalho foi determinar a influência alelopática de extratos aquosos de folhas de Phytolacca dioica L. na germinação e crescimento inicial de plantas de tomate e picão-preto. Extratos foram preparados nas concentrações 1\%,2\%, 4\% e 8\%. Foram medidos o pH e o potencial osmótico dos extratos e realizada a análise fitoquímica das folhas. Nos experimentos foram utilizadas quatro repetições de 25 sementes distribuídas em placas de Petri com duas folhas de papel germitest umedecida com $5 \mathrm{~mL}$ de extrato. Foi avaliada a porcentagem de germinação (PG), velocidade de germinação (VG), índice de velocidade de germinação (IVG), comprimento (raiz e parte aérea) e massa (fresca e seca) das plântulas de tomate e picão-preto. $\mathrm{O} \mathrm{pH}$ e o potencial osmótico mantiveram-se dentro de padrões aceitáveis e a análise fitoquímica das folhas revelou a presença de flavonóides. A PG, VG e IVG foram afetados nos tratamentos mais concentrados (4 e 8\%), o comprimento e a massa das plântulas de tomate e picão-preto foram afetados em todos os tratamentos. Tratamentos a $8 \%$ inibiram totalmente o processo germinativo das plantas.

Unitermos: alelopatia, crescimento inicial, germinação, umbu

\section{Abstract}

Allelopathic influence of Phytolacca dioica L. germination and early growth of Lycopersicum esculentum and Bidens pilosa. Allelopathy refers to the ability that a plant has to interfere in the metabolism of another by means of chemical compounds released into the environment. The objective of this study was to determine the allelopathic effect of aqueous extracts of leaves of Phytolacca dioica L. on the germination and early growth of tomato plants and Bidens pilosa. Extracts were prepared at concentrations of 1\%,2\%, 4\% and $8 \%$. We measured the $\mathrm{pH}$ and osmotic potential of the extracts and carried out a phytochemical analysis of the leaves. In our experiments we used four replicates of 25 seeds distributed in Petri dishes with two sheets of germitest paper dampened with $5 \mathrm{~mL}$ extract. We evaluated the percentage of germination (PG), speed of germination (VG), speed of germination index (IVG), and length (root and shoot) and mass (fresh and dry) of seedlings of tomato and Bidens pilosa. The $\mathrm{pH}$ and osmotic potential were found to be within acceptable standards and the phytochemical analysis of the leaves showed the presence of flavonoids. PG, VG and IVG were affected in more concentrated treatments (4 and $8 \%$ ), and the length and mass of seedlings of tomato and Bidens pilosa were affected in all treatments. Treatments at an $8 \%$ concentration completely inhibited the germination process of the plants.

Key words: allelopathy, early growth, germination, Phytolacca dioica 


\section{Introdução}

As plantas têm capacidade de produzir substâncias químicas que podem contribuir para sua sobrevivência e ou desenvolvimento de mecanismos de defesa (Rice, 1984). Essas substâncias são metabólitos bioativos (aleloquímicos) oriundos do metabolismo secundário (Alves et al., 2004), entre eles taninos, glicosídeos cianogênicos, alcalóides, sesquiterpenos, flavonóides e ácidos fenólicos, entre outros, apresentam atividade alelopática (King e Ambika, 2002).

Os metabólitos podem ser liberados naturalmente pelas plantas que os produz. No meio ambiente eles podem ocasionar interferência em outras plantas podendo prejudicá-las ou favorecê-las, de forma direta ou indireta (Ferreira e Aquila, 2000). Quando os metabólitos agem negativamente a germinação das sementes e o crescimento das plantas são as etapas mais afetadas (Rice, 1984; Chon e Kim, 2004). Estas substâncias podem estar envolvidas em complexos processos ambientais de ecossistemas naturais ou manejados. A diversidade de espécies, dominância, sucessão e clímax em vegetação natural e a produtividade de agroecossistemas podem ser determinadas pela atividade alelopática de aleloquímicos liberados no meio (Chou, 1999).

Os efeitos alelopáticos observados são resultados de uma interação extremamente complexa entre fatores genéticos e ambientais (Rodrigues et al., 1999) e, embora, as plantas tenham capacidade de produzir aleloquímicos em todos os seus órgãos, sua concentração nos tecidos depende de diversos fatores, como solo, temperatura e pluviosidade, e essa produção tem fundamental importância no que diz respeito à auto defesa (Macías et al., 2007). Os aleloquímicos são liberados no meio ambiente pelas plantas por diferentes vias de eliminação (volatilização, exsudação radicular, lixiviação e decomposição de resíduos). Para que a ação seja eficaz a liberação dos aleloquímicos deve ser continua, de modo que seus efeitos persistam até as culturas subsequentes. (Rodrigues et al., 1999).

Esforços vêm sendo envidados nos últimos anos, especialmente com espécies arbóreas, a fim de verificar propriedades alelopáticas em espécies com potencial para compor sistemas agroflorestais e silvipastoris (Ferreira et al., 1992; Zhang, 1993).
Estudos alelopáticos podem ser úteis na busca por fitotoxinas naturais e de derivados sintéticos a serem empregados como herbicidas naturais, pois podem ser mais específicos em sua ação e menos prejudiciais ao meio ambiente (Smith e Martin, 1994; Macías et al., 1998; Chou, 1999). Desta forma reduz-se ou eliminase a contaminação do ambiente, preservando recursos naturais e garantindo a produção de produtos agrícolas com alta qualidade, desprovidos de resíduos de agentes contaminantes (Souza Filho e Alves, 2002).

$\mathrm{O}$ umbu (Phytolacca dioica L.) pertence à família Phytolaccaceae. É uma planta nativa de ocorrência nas regiões centro-oeste, sudeste e sul do Brasil. A planta é decídua, característica de matas densas e formações secundárias. É considerada planta de padrão de boa terra, pioneira e de rápido crescimento, utilizada em plantios mistos, em áreas degradadas de preservação permanente e muito recomendada para o paisagismo. Sua madeira é leve, macia, muito porosa e de baixíssima resistência ao apodrecimento e sem aplicação prática conhecida (Lorenzi, 2000).

Estudos sobre a ação alelopática de espécies nativas ainda é pouco conhecido. Há uma complexa e diversificada linguagem de interações químicas plantaplanta, o que se torna uma necessidade eminente o entendimento mais acurado, já que áreas imensas de vegetações nativas vêm sendo destruídas sem sequer tenha se conhecido o seu potencial e os benefícios que podem proporcionar (Larcher, 2004).

Não tendo sido encontrados relatos sobre a ação ou competição desta planta em relação a outras e considerando observações feitas a campo objetivaramse a pesquisa das influências alelopáticas de Phytolacca dioica L. (umbu) na germinação e crescimento inicial de tomate e picão-preto.

\section{Material e Métodos}

Os experimentos foram conduzidos no Laboratório de Fisiologia Vegetal da Universidade Regional Integrada do Alto Uruguai e das Missões - Campus de Frederico Westphalen, de novembro de 2007 a junho de 2008. Foram utilizadas, como material vegetal, folhas 
frescas de umbu, coletadas em formações vegetais do Médio Alto Uruguai do Estado do Rio Grande do Sul. Como espécies alvos, foram utilizadas sementes de tomate (Lycopersicum esculentum L. cv. "Santa Cruz Kada"), obtidos no comércio local e sementes de picãopreto (Bidens pilosa L.) obtidas a campo.

Folhas frescas foram trituradas em liquidificador industrial, na proporção de $8 \mathrm{~g}$ para $100 \mathrm{~mL}$ de água destilada por $5 \mathrm{~min}$ em temperatura ambiente. $\mathrm{O}$ extrato bruto obtido permaneceu $24 \mathrm{~h}$ em repouso, no escuro e sob refrigeração $\left( \pm 10^{\circ} \mathrm{C}\right)$, decorrido este período, foi filtrado em gaze, seguindo-se centrifugação a 3000rpm por 10min. O sobrenadante foi utilizado como extrato de maior concentração $(8 \%-\mathrm{m} / \mathrm{v})$. Repetiram-se os procedimentos e diluíram-se em água destilada para a obtenção de extratos nas concentrações de 4\%,2\% e 1\% $(\mathrm{m} / \mathrm{v})$. Como tratamento controle utilizou-se somente água destilada, a fim de comparar com os efeitos das quatro concentrações. Os extratos das folhas foram avaliados individualmente quanto ao $\mathrm{pH}$, aferindo-se com pHmetro (Tecnal), e potencial osmótico, estimado pelo método de Chardakov (Salisbury e Ross, 1992). Também foram realizadas análises fitoquímicas da folhas, via detecção de compostos de metabolismo secundário: taninos, saponinas, flavonóides e alcalóides, de acordo com métodos propostos por Costa (2001) e Falkenberg et al. (2002).

Os experimentos foram inteiramente casualizados com 4 repetições de 25 sementes para cada tratamento, distribuídas aleatoriamente em placas de Petri esterilizadas de $9 \mathrm{~cm}$ de diâmetro contendo duas folhas de papel germitest umedecidas com $5 \mathrm{~mL}$ de extrato aquoso, de modo que a solução estivesse bem distribuída. As placas contendo, devidamente, suas sementes e extratos, permaneceram em câmara de germinação tipo BOD, a temperatura constante igual a $25^{\circ} \mathrm{C}$ em presença de luz. Foram testadas todas as concentrações dos extratos para cada planta alvo. As sementes de picão-preto foram previamente desinfestadas com hipoclorito de sódio a $2 \%$, por $30 \mathrm{~min}$, seguido de cinco enxágues com água destilada.

O registro da germinação foi realizada em intervalos de $24 \mathrm{~h}$ durante 7 dias, considerando-se como critério de germinação a curvatura geotrópica da raiz
(Ferreira e Aquila, 2000). Para análise da germinação foram considerados os parâmetros: porcentagem de germinação (PG), velocidade de germinação (VG), índice de velocidade de germinação (IVG), calculados de acordo com fórmulas citadas por Vieira e Carvalho (1994) e coeficiente de uniformidade da germinação (CUG), de acordo com Santana e Ranal (2004).

Para análise do crescimento inicial consideraram-se os parâmetros: comprimento (da raiz e da parte aérea) e massa (fresca, seca e conteúdo de água). O comprimento da raiz e da parte aérea foi obtido de 10 plântulas por placa, totalizando 40 plântulas por tratamento, decorridos sete dias da instalação do experimento, utilizando-se papel milimetrado (a análise de crescimento procedeuse a partir das plântulas germinadas do experimento de germinação). Posteriormente obteve-se a massa fresca das amostras, por meio de pesagem em balança analítica, em seguida as amostras foram acondicionadas em sacos de papel e colocadas em estufa de secagem por sete dias a $40^{\circ} \mathrm{C}$, do qual se obteve a massa seca. Também foi calculado o conteúdo de água (\%) de acordo com fórmula citada por Marenco e Lopes (2005). Como o conteúdo de água pode variar ao longo do dia, dependendo do momento de sua utilização, as amostras de massa fresca foram pesadas imediatamente a sua retirada do germinador e as amostras de massa seca foram pesadas imediatamente a sua retirada da estufa de secagem.

Os dados obtidos foram submetidos à ANOVA, comparados pelo teste de Tukey a $1 \%$ de probabilidade, usando o programa Estat-Sistema de análises estatísticas $($ V.2,0) Unesp - Jaboticabal.

\section{Resultados e Discussão}

Comparando as diferentes concentrações dos bioensaios (tomate e picão-preto), registrou-se interferência significativa na germinação de sementes para os parâmetros (porcentagem de germinação, velocidade de germinação e índice de velocidade de germinação). O processo germinativo de sementes de tomate e picãopreto foi influenciado significativamente pelos extratos de folhas de umbu a partir dos tratamentos submetidos à concentração 4\%. As sementes de tomate e picão-preto submetidas à concentração $8 \%$ do extrato apresentaram 
efeitos drásticos, ocorrendo inibição completa da germinação. Comparando demais tratamentos ao controle, tratamentos a $1 \%$ e $2 \%$ do extrato, submetidos a extratos de folhas de umbu, não apresentaram significativa redução da porcentagem de germinação das sementes em ambos os bioensaios (Figura 1).

Esses resultados são semelhantes aos obtidos por Gorla e Perez (1997), no qual extratos de maiores concentrações de Miconia albicans e Lantana camara diminuíram as taxas de germinação de sementes de tomate. O mesmo ocorre com sementes de picão-preto que tiveram a porcentagem de germinação reduzida devido à ação de comigo-ninguém-pode (Dieffenbachia picta), (Hoffmann et al., 2007).

Periotto et al. (2004) verificaram que extratos de caules e de folhas de Andira humilis, na concentração $16 \%(\mathrm{p} / \mathrm{v})$, produziram efeitos inibitórios significativos na porcentagem de germinação de sementes de alface. Para sementes de rabanete, apenas extratos de caule a $16 \%$ provocaram efeitos inibitórios, sendo que as demais concentrações não provocaram alterações inibitórias nas sementes de alface e rabanete.
A velocidade de germinação das sementes dos bioensaios com tomate e picão-preto foi alterada pelos extratos de folhas de umbu. A velocidade de germinação das sementes de tomate e picão-preto submetidas às concentrações 2 e $4 \%$ levaram um período (dias) maior para germinar em relação ao tratamento controle e ao tratamento com extrato a $1 \%$, diferindo significativamente. No tratamento com concentração $8 \%$ do extrato de folhas de umbu, de ambos os bioensaios, não ocorreu germinação das sementes (Figura 2).

Gorla e Perez (1997) observaram decréscimos na velocidade de germinação de sementes de tomate com o aumento da concentração de extratos de Miconia albicans, Lantana camara, Leucaena leucocephala e Drimys winteri. Quando sementes de pepino foram submetidas aos extratos, apenas L. camara causaram atraso na velocidade de germinação. Gatti et al. (2004) constataram decréscimos na velocidade de germinação de sementes de rabanete devido à ação de extratos aquosos de raiz, caule, folha, flor e fruto de Aristolochia esperanzae, os decréscimos se intensificaram com o aumento das concentrações comparado ao controle.

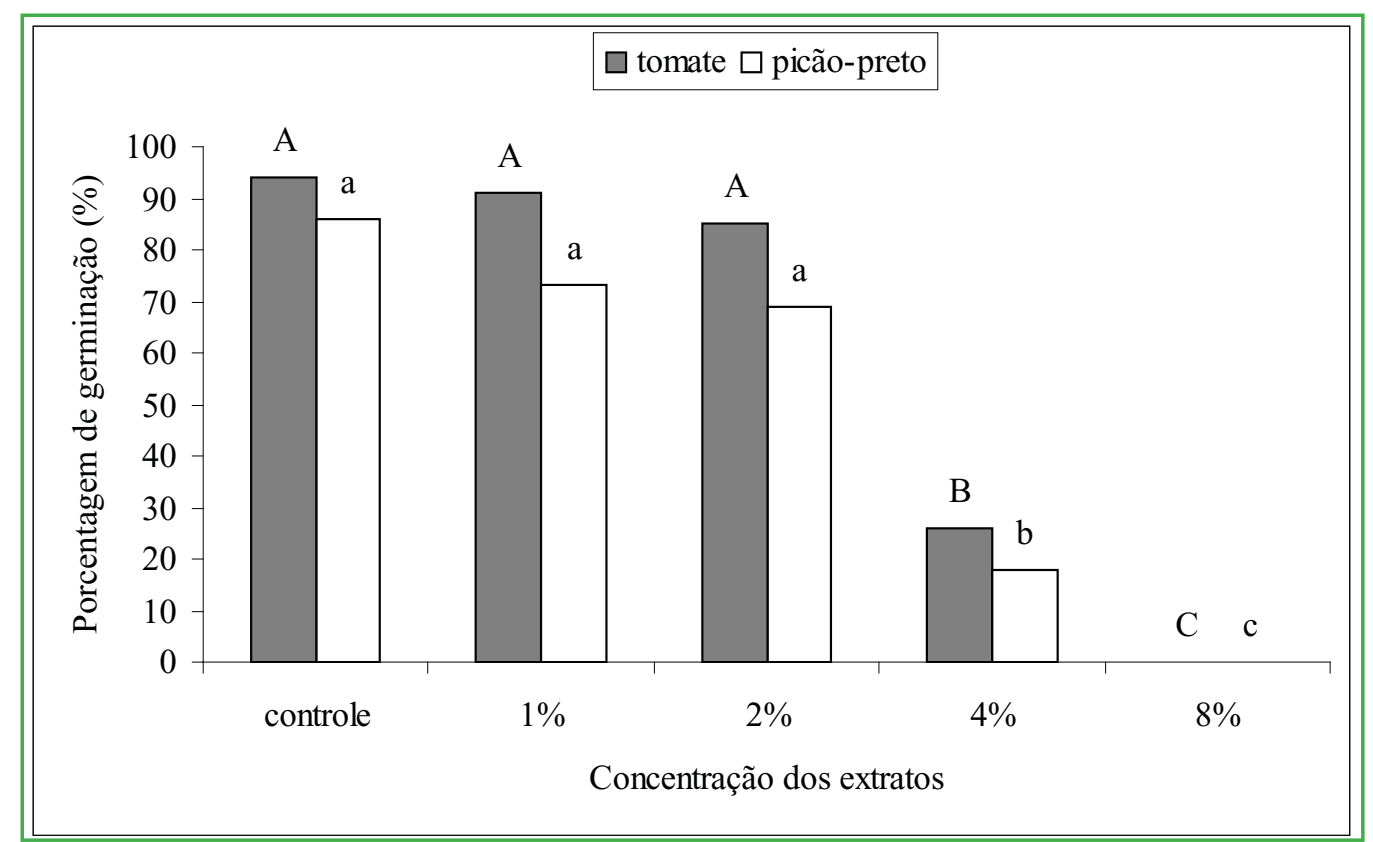

FIGURA 1: Porcentagem de germinação (PG) de sementes de tomate e picão-preto, sob efeito de concentrações dos extratos aquosos de folhas de umbu (médias seguidas pelas mesmas letras maiúsculas para sementes de tomate e minúsculas para sementes de picão-preto, não diferem pelo teste de Tukey a $1 \%$ de probabilidade). 


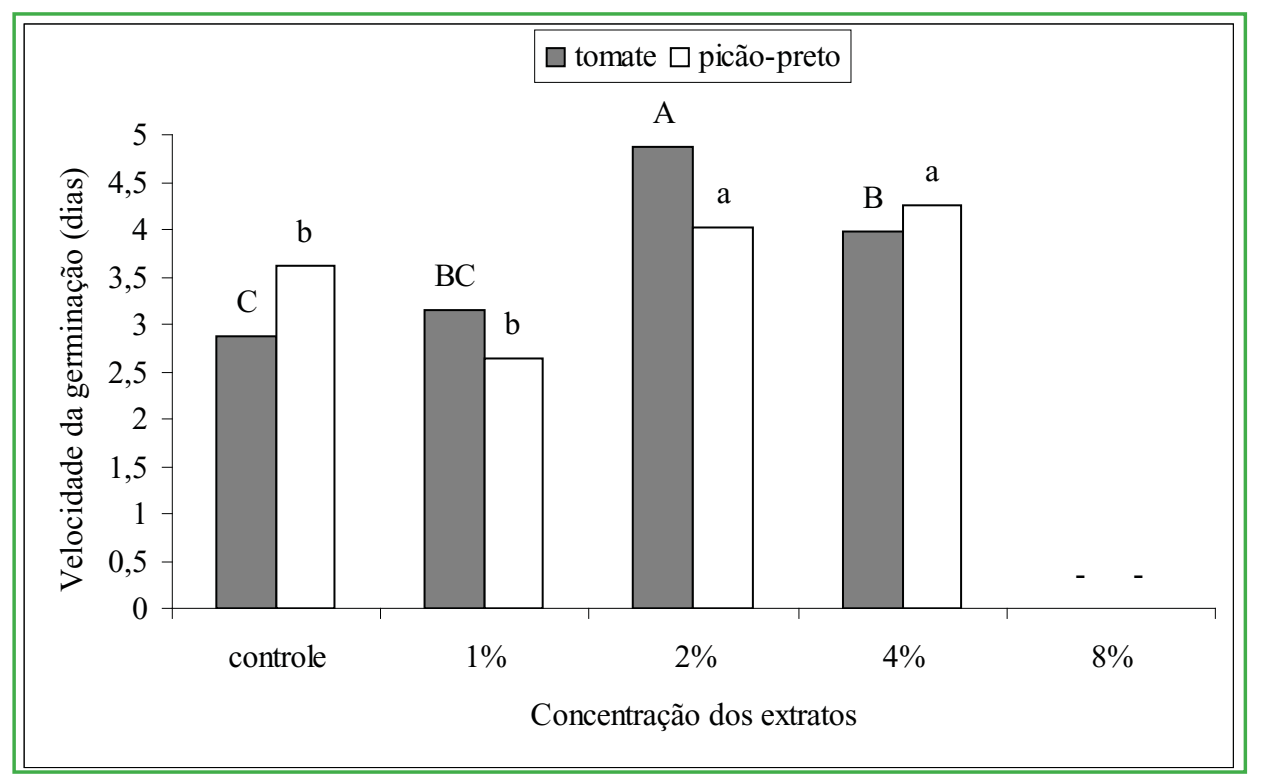

FIGURA 2: Velocidade de germinação (dias) de sementes de tomate e picão-preto, sob efeito de concentrações dos extratos aquosos de folhas de umbu (médias seguidas pelas mesmas letras maiúsculas para sementes de tomate e minúsculas para sementes de picão-preto, não diferem pelo teste de Tukey a $1 \%$ de probabilidade). (-) análise não realizada.

No índice de velocidade de germinação, para o bioensaio com sementes de tomate o tratamento controle e o tratamento submetido a extratos de folhas de umbu na concentração $1 \%$ não diferem significativamente, no entanto a partir do tratamento com sementes submetido à concentração $2 \%$ observou-se redução do número médio de sementes germinadas por dia, a redução é proporcional ao aumento da concentração dos extratos. Para o bioensaio com sementes de picão-preto, $o$ tratamento submetido à concentração $1 \%$ observou-se tendência de um número maior de sementes germinadas por dia em relação ao tratamento controle. Contudo, não se pode afirmar com segurança tratar-se de estímulo pois não houve diferenças significativas na porcentagem e na velocidade de germinação desses tratamentos (Figuras 1 e 2). No entanto, esse registro ocorre apenas nesse tratamento, pois à medida que se aumentam as concentrações dos extratos o número de sementes germinadas por dia diminui significativamente (Figura 3).

Teixeira et al. (2004) observaram reduções no índice de velocidade de germinação de sementes de picãopreto submetidas à concentração $12 \%$ de extratos de mucuna-preta (Stilozobium aterrimum), para testes com Crotalaria spectabilis, Crotalaria juncea, Stilozobium sp. e Cajanus cajan houve tendência a redução do IVG, no entanto não diferiram do controle.
Os resultados obtidos nos testes com extratos de folhas de umbu sobre tomate e picão-preto não corroboram com dados citados por Ferreira e Aquila (2000). Estes citam que os efeitos alelopáticos geralmente não se dão sobre a germinabilidade, ou seja, percentual final de germinação, mas sobre a velocidade de germinação ou outros parâmetros testados. Pelo mesmo fato também não corroboram com resultados de Miró et al. (1998) e Maraschin-Silva e Aquila (2006a; 2006b) em testes alelopáticos.

Segundo Santana e Ranal (2004), o coeficiente de uniformidade da germinação é muito importante, pois permite avaliar o comportamento germinativo das sementes de uma amostra. Comparando as amostras, consideram-se uniformes aquelas que apresentam valores de uniformidades maiores em relação às outras. Segundo a Tabela 1, para a germinação de sementes de tomate os tratamentos controle e $4 \%$ apresentaram maior uniformidade na germinação em relação aos demais tratamentos submetidos aos extratos de folhas de umbu. Para as sementes de picão-preto a germinação do tratamento controle é mais uniforme em relação aos demais tratamentos (1, 2 e 4\%). Em ambos os bioensaios tratamento $8 \%$ não há uniformidade visto que não ocorreu germinação. 


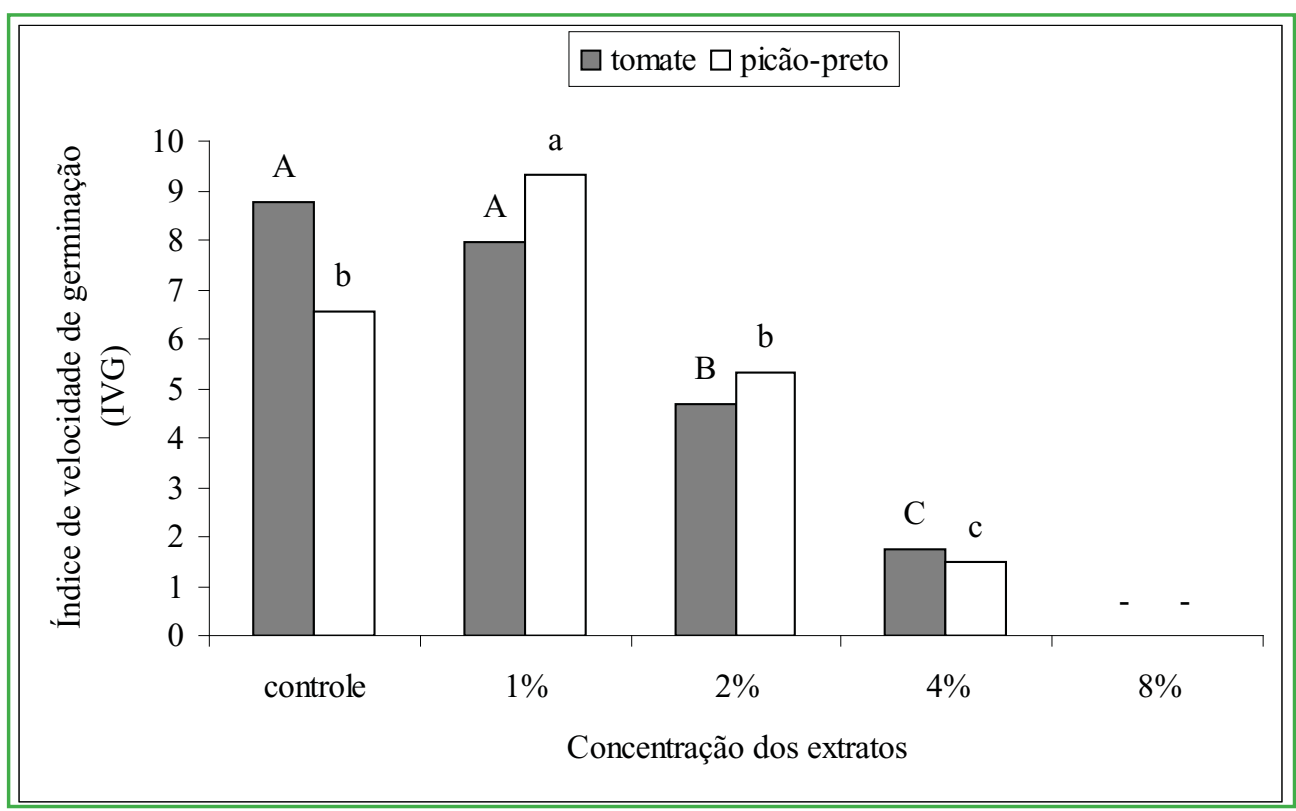

FIGURA 3: Índice de velocidade de germinação (IVG) de sementes de tomate e picão-preto, sob efeito de concentrações dos extratos aquosos de folhas de umbu (médias seguidas pelas mesmas letras maiúsculas para sementes de tomate e minúsculas para sementes de picão-preto, não diferem pelo teste de Tukey a 1\% de probabilidade). (-) análise não realizada.

Para o crescimento inicial, os extratos provocaram alterações nos parâmetros de comprimento e massa (fresca, seca e conteúdo de água) das plântulas. O comprimento da raiz de plântulas de tomate e picão-preto foi afetado significativamente devido à ação dos extratos de folhas de umbu, com redução do comprimento proporcional ao aumento da concentração dos extratos, comparado aos seus respectivos tratamentos controle. Os extratos causaram anormalidades, principalmente no sistema radicular, com o aparecimento de raízes primárias atrofiadas, defeituosas e ausentes em alguns casos. Certas plântulas também apresentaram raízes curtas e desproporcionais comparando as demais estruturas da planta (Tabela 2).

TABELA 1: Valores médios do coeficiente de uniformidade da germinação $\left(\mathrm{dia}^{-2}\right)$ de sementes de tomate e picão-preto sob efeito de concentrações dos extratos aquosos de folhas de umbu.

\begin{tabular}{ccc}
\hline Tratamento & tomate & picão-preto \\
\hline Controle & $1,886 \mathrm{a}^{*}$ & $1,117 \mathrm{a}$ \\
$1 \%$ & $1,247 \mathrm{~b}$ & $0,584 \mathrm{~b}$ \\
$2 \%$ & $0,897 \mathrm{~b}$ & $0,447 \mathrm{~b}$ \\
$4 \%$ & $1,900 \mathrm{a}$ & $0,427 \mathrm{~b}$ \\
$8 \%$ & - & - \\
\hline
\end{tabular}

*letras minúsculas comparando os tratamentos em cada coluna. Letras iguais não diferem pelo teste de Tukey a $1 \%$ de probabilidade. (-) análise não realizada.
A parte aérea das plântulas também foi afetada. Observa-se que, tanto para plântulas de tomate quanto de picão-preto os tratamentos com plântulas submetidas a extratos de folha de umbu na concentração $1 \%$ apresentaram comprimento significativamente maior em relação ao tratamento controle. No entanto o comprimento foi reduzido a partir dos tratamentos submetidos à concentração $2 \%$, correspondendo ao aumento da concentração dos extratos. Tratamento $4 \%$ de ambos os bioensaios (tomate e picão-preto) apresentou drástica redução do comprimento (raiz e parte aérea). O tratamento $8 \%$ não houve crescimento tendo em vista a inibição total da germinação das sementes de ambos os bioensaios (Tabela 2).

Segundo Hoffmann et al. (2007), sementes de picão-preto tiveram o comprimento radicular e da parte aérea reduzidos significativamente, à medida que se aumentaram as concentrações de extratos aquosos de espirradeira (Nerium oleander). Maraschin-Silva e Aquila (2006a) constataram que as plântulas de alface tiveram reduções acentuadas no comprimento radicular quando submetidas a extratos de Erythroxylum argentium e Ocotea puberula, extratos de Luehea divaricata e Myrsine guianensis embora tenham provocado reduções no comprimento radicular, as respostas não foram 
acentuadas. Analisando o comprimento do hipocótilo E. argentium, L. divaricata e M guianensis provocaram aumentos no comprimento em relação ao tratamento controle e $O$. puberula provocou redução.

TABELA 2: Valores médios do comprimento da raiz e da parte aérea $(\mathrm{cm})$ de plântulas de tomate e picão-preto, sob efeito de concentrações dos extratos aquosos de folhas de umbu.

\begin{tabular}{ccccc}
\hline \multirow{2}{*}{ Tratamento } & \multicolumn{2}{c}{ tomate } & \multicolumn{2}{c}{ picão-preto } \\
\cline { 2 - 5 } & raiz & $\begin{array}{c}\text { parte } \\
\text { aérea }\end{array}$ & raiz & $\begin{array}{c}\text { parte } \\
\text { aérea }\end{array}$ \\
\hline controle & $8,72 \mathrm{a}^{*}$ & $2,86 \mathrm{~b}$ & $3,34 \mathrm{a}$ & $2,23 \mathrm{~b}$ \\
$1 \%$ & $6,04 \mathrm{~b}$ & $4,59 \mathrm{a}$ & $1,55 \mathrm{~b}$ & $2,52 \mathrm{a}$ \\
$2 \%$ & $2,12 \mathrm{c}$ & $2,93 \mathrm{~b}$ & $0,66 \mathrm{c}$ & $1,50 \mathrm{c}$ \\
$4 \%$ & $0,06 \mathrm{~d}$ & $0,28 \mathrm{c}$ & $0,04 \mathrm{~d}$ & $0,20 \mathrm{~d}$ \\
$8 \%$ & - & - & - & - \\
\hline
\end{tabular}

* letras minúsculas comparando os tratamentos em cada coluna. Letras iguais não diferem pelo teste de Tukey a $1 \%$ de probabilidade. (-) análise não realizada.

O processo de germinação é menos sensível aos aleloquímicos em relação ao crescimento inicial das plântulas, visto que, para cada semente o fenômeno é discreto, germinando ou não (Ferreira e Aquila, 2000; Ferreira, 2004). Para o crescimento inicial, as substâncias alelopáticas podem induzir o aparecimento de plântulas anormais, com raízes primárias atrofiadas e defeituosas, ausência de raízes secundárias e necrose radicular, bem como disparidades no tamanho estrutural das plântulas (Gatti et al., 2004; Periotto et al., 2004; Maraschin-Silva e Aquila, 2006a; 2006b). As raízes mostram-se mais sensíveis à ação de substâncias presentes nos extratos quando comparadas com as demais estruturas das plântulas (Chon et al., 2000). Isso se deve ao fato das raízes estarem em contato direto e prolongado ao extrato (aleloquímicos) em relação às demais estruturas das plântulas (Chung et al., 2001).

Observou-se diferenças na massa fresca e seca das plântulas de tomate nos tratamentos 2 e $4 \%$ dos extratos aquosos de folhas de umbu, tratamento $8 \%$ não ocorreu germinação, portanto, não apresentou matéria para análise de massa. O conteúdo de água das plântulas de tomate se mostrou menor apenas no tratamento submetido à concentração $4 \%$, diferindo dos demais tratamentos (Tabela 3).

Quanto ao bioensaio com plântulas de picão-preto, não se observa alterações significativa nos parâmetros analisados (massa fresca, massa seca e conteúdo de água), exceto para massa seca de plântulas submetidas à concentração $2 \%$, que difere do tratamento controle. Tratamentos submetidos à concentração 4 e $8 \%$ de extratos aquosos de folhas de umbu não apresentaram matéria suficiente para análise (Tabela 3).

Medeiros e Lucchesi (1993) não verificaram influências no peso da matéria seca de plântulas de alface submetidas a extratos de ervilhaca (Vicia sativa). Hoffmann et al. (2007) observaram redução das massas frescas e secas das plântulas de alface e picão-preto submetidas a extratos de espirradeira e comigoninguém-pode, a redução é proporcional ao aumento da concentração dos extratos. O mesmo autor ainda cita que a redução das massas das plântulas é um reflexo da redução das estruturas das plântulas devido à ação dos extratos.

Segundo Marenco e Lopes (2005), o conteúdo de água nas diferentes partes da planta pode variar enormemente, em geral os tecidos verdes da maioria dos vegetais apresentam um conteúdo médio de água superior a $80 \%$.

TABELA 3: Valores médios da massa fresca (MF), da massa seca (MS) e conteúdo de água (CA) de plântulas de tomate e picão-preto, sob efeito de concentrações dos extratos aquosos de folhas de umbu.

\begin{tabular}{ccccccc}
\hline \multirow{2}{*}{ Tratamento } & \multicolumn{3}{c}{ tomate } & \multicolumn{3}{c}{ picão-preto } \\
\cline { 2 - 7 } & MF (g) & MS (g) & CA (\%) & MF (g) & MS (g) & CA (\%) \\
\hline controle & $0,351 \mathrm{~b}^{*}$ & $0,015 \mathrm{~b}$ & $95,735 \mathrm{a}$ & $0,061 \mathrm{~ns}$ & $0,006 \mathrm{a}$ & $90,243 \mathrm{~ns}$ \\
$1 \%$ & $0,413 \mathrm{a}$ & $0,019 \mathrm{a}$ & $95,278 \mathrm{a}$ & $0,065 \mathrm{~ns}$ & $0,005 \mathrm{ab}$ & $91,538 \mathrm{~ns}$ \\
$2 \%$ & $0,287 \mathrm{c}$ & $0,014 \mathrm{~b}$ & $94,956 \mathrm{ab}$ & $0,061 \mathrm{~ns}$ & $0,003 \mathrm{~b}$ & $93,877 \mathrm{~ns}$ \\
$4 \%$ & $0,113 \mathrm{~d}$ & $0,007 \mathrm{c}$ & $93,846 \mathrm{~b}$ & - & - & - \\
$8 \%$ & - & - & - & - & - & - \\
\hline
\end{tabular}

*letras minúsculas comparando os tratamentos em cada coluna. Letras iguais não diferem pelo teste de Tukey a 1\% de probabilidade. (ns) não significativo. (-) análise não realizada. 
A caracterização físico-química dos extratos aquosos revelou, quanto ao $\mathrm{pH}$ dos extratos de umbu, baixa variação de valores e baixa acidez, variando entre 6,46 e 6,90. Os valores de potencial osmótico apresentaram variação entre $-0,0073$ e $-0,0549 \mathrm{MPa}$. (Tabela 4).

TABELA 4: Características físico-químicas de extratos aquosos de folhas de umbu.

\begin{tabular}{ccc}
\hline Concentração & $\mathbf{p H}$ & PO* $\left.^{*} \mathbf{M P a}\right)$ \\
\hline controle & 7,01 & 0,0000 \\
$1 \%$ & 6,73 & $-0,0073$ \\
$2 \%$ & 6,90 & $-0,0146$ \\
$4 \%$ & 6,81 & $-0,0292$ \\
$8 \%$ & 6,46 & $-0,0549$ \\
\hline
\end{tabular}

* PO (potencial osmótico).

Valores semelhantes de $\mathrm{pH}$ foram obtidos por Maraschin-Silva e Aquila (2006a e 2006b) para os extratos testados em efeitos alelopáticos envolvendo alface como planta alvo. Semelhantes pHs também foram obtidos por Periotto et al. (2004) para extratos aquosos de Andira humulis.

$\mathrm{O} \mathrm{pH}$ e o potencial osmótico mantiveram-se dentro de padrões aceitáveis no que se considera adequado para a germinação e crescimento inicial (Aquila, 2000). Gatti et al. (2004) recomendam que o potencial osmótico de extratos envolvendo testes de germinação não ultrapasse valores -0,2 MPa. Extratos aquosos podem apresentar determinados solutos que podem alterar a propriedade da água, resultando numa pressão osmótica diferente de zero na solução (Villela et al., 1991). Tais solutos como açúcares, aminoácidos e ácidos orgânicos podem mascarar o efeito alelopático dos extratos por interferir no $\mathrm{pH}$ e serem osmoticamente ativos (Ferreira e Aquila, 2000).

As reações de deteç̧ão de aleloquímicos revelaram a presença de flavonóides nas folhas de umbu (Tabela 5).

TABELA 5: Detecção de aleloquímicos em folhas de umbu.

\begin{tabular}{cc}
\hline Análise fitoquímica & Folhas \\
\hline taninos & $-*$ \\
saponinas & - \\
flavonóides & $+* *$ \\
alcalóides & - \\
\hline
\end{tabular}

* - (ausência), ** + (presença)
Tal constituinte químico pode variar em quantidade e qualidade na planta. Representa uma importante classe de polifenóis e sua presença em vegetais parece estar relacionada com funções de defesa, controle de hormônios vegetais, inibição de enzimas e agentes alelopáticos (Souza Filho e Alves, 2002). Chaves et al. (2001) citam que a presença de flavonóides com atividades fitotóxicas não é restrita em folhas de plantas de Cistus ladanifer, podendo aparecer em outros órgãos, flavonóides também foram encontrados no solo, especialmente os grupos com maior atividade fitotóxica, o que permite concluir que esta planta tem capacidade de exudar quantidade considerável deste composto. Segundo Kong et al. (2004), o arroz apresenta flavonas e ciclohexano que são responsáveis por atividades inibitórias de ervas daninhas e agentes patogênicos.

Diante da metodologia utilizada e dos resultados obtidos, foi possível concluir que:

- houve interferência na PG, VG, IVG, CUG, comprimento radicular e da parte aérea e na massa fresca e seca das plântulas de tomate e picão-preto submetidas aos extratos de folhas de umbu.

- os efeitos tóxicos sobre as plântulas de tomate e picão-preto foram crescentes à medida que a concentração dos extratos de folhas de umbu foi aumentada. $\mathrm{O}$ tratamento mais concentrado $(8 \%)$ apresentou efeitos drásticos.

- a inibição da germinação e necrose radicular foram os efeitos/sintomas mais significativos na germinação/crescimento inicial das plântulas de tomate e picão-preto.

\section{Referências}

Alves, M. da C. S.; Medeiros Filho, S.; Innecco, R.; Torres, S.B. 2004. Alelopatia de extratos voláteis na germinação de sementes e no comprimento da raiz de alface. Pesquisa Agropecuária Brasileira, 39 (11): 1083-1086.

Aquila, M. E. A. 2000. Efeito alelopático de Ilex paraguariensis A. St.-Hil. na germinação e crescimento inicial de Lactuca sativa L. Iheringia, 53: 51-66.

Chaves, N.; Sosa, T.; Escudero, J. C. 2001. Plant growth inhibiting flavonoids in exudates of Cistus ladanifer and in associated soils. Journal of Chemical Ecology, 27 (3): 623-631. 
Chon, S. U.; Coutts, J. H.; Nelson, C. J. 2000. Effects of light, growth media, and seedling orientation on bioassays of alfalfa autotoxicity. Agronomy Journal, 92: 715-720.

Chon, S. U.; Kim, Y. M. 2004. Herbicidal potential and quantification of suspected allelochemicals from four grass crop extracts. Journal Agronomy \& Crop Science, 190: 145-150.

Chou, C. H. 1999. Roles of allelopathy in plant biodiversity and sustainable agriculture. Critical Reviews in Plant Sciences, 18 (5): 609-630.

Chung, I. M.; Ahn, J. K.; Yun, S. J. 2001. Assessment of allelopathic potential of barnyard grass (Echinochloa crus-gall) on rice (Oriza sativa L.) cultivars. Crop Protection, 20: 921-928.

Costa, A.F. 2001. Farmacognosia. Fundação Calouste Gulbenkian, Lisboa, Portugal, 992pp.

Falkenberg, M. B.; Santos, R. I.; Simões, C. M. O. 2002. Introdução à análise fitoquímica. In: Simões, C. M. O.; Schenkel, E. P.; Gosmsnn, G.; Mello, J. C. P.; Mentz, L. A. \& Petrovick, P. R. Farmacognosia: Da planta ao medicamento. UFRGS/UFSC, Porto alegre/Florianópolis, Brasil, p.165-182.

Ferreira, A. G. 2004. Interferência: Competição e alelopatia. In: Ferreira, A. G. \& Borghetti, F. (Eds). Germinação do básico ao aplicado. Artmed, Porto Alegre, Brasil, p.252-262.

Ferreira, A. G.; Aquila, M. E. A. 2000. Alelopatia: Uma área emergente da ecofisiologia. Revista Brasileira de Fisiologia Vegetal, 12: 175-204.

Ferreira, A. G.; Aquila, M. E. A.; Jacobi, U. S.; Rizvi, V. 1992 Allelopathy in Brazil. In: Rizvi, S. J. H. \& Rizvi, V. (Eds). Allelopathy: Basic and applied aspects. Chapman \& Hall, London, UK, p.243-250.

Gatti, A. B.; Perez, S. C. J. G. A.; Lima, M. I. S. 2004. Efeito alelopático de Aristolochia esperanzae O. Kuntze na germinação e no crescimento de Lactuca sativa L. e Raphanus sativus L. Acta Botanica Brasilica, 18 (3): 459-472.

Gorla, C. M.; Perez, S. C. J. G. A. 1997. Influência de extratos aquosos de Miconia albicans Triana, Lantana camara L., Leucaena leucocephala (Lam) de Wit e Drimys winteri Forts, na germinação e crescimento inicial de sementes de tomate e pepino. Revista Brasileira de Sementes, 19 (2): 260-265.

Hoffmann, C. E. F.; Neves, L. A. S.; Bastos, C. F.; Wallau, G. L. 2007. Atividade alelopática de Nerium Oleander L. e Dieffenbachia picta schott em sementes de Lactuca Sativa L. e Bidens pilosa L. Revista de Ciências Agroveterinárias, 6 (1): 11-21.

King, S. R.; Ambika, R. 2002. Allelopathic plants. 5. Chromolaen odorata (L.). Allelopathy Journal, 9 (1): 35-41.

Kong, C.; Xu, X.; Zhou, B.; Hu, F.; Zhang, C.; Zhang, M. 2004. Two compounds from allelopathic rice accession and their inhibitory activity on weeds and fungal pathogens. Phytochemistry, 65: 1123-1128.

Larcher, W. 2004. Ecofisiologia Vegetal. Rima, São Carlos, Brasil, $531 \mathrm{pp}$.

Lorenzi, H. 2000. Árvores brasileiras: Manual de identificação e cultivo de plantas arbóreas nativas do Brasil. Nova Odessa, Instituto Plantarum, São Paulo, Brasil, 352pp.
Macías, F. A.; Molinillo, J. M. G.; Varela, R. M.; Galindo, J. C. G. 2007. Allelopathy - A natural alternative for weed Control. Pest Management Science, 63: 327-348.

Macías, F. A.; Varela, R. M.; Torres, A.; Oliva, R. M.; Molinillo, J. M. G. 1998. Bioactive norsesquiterpenes from Helianthus annuus with potential allelopathic activity. Phytochemistry, 48 (4): 631636.

Maraschin-Silva, F.; Aquila, M. E. A. 2006a. Contribuição ao estudo do potencial alelopático de espécies nativas. Revista Árvore, 30 (4): 547-555.

Maraschin-Silva, F.; Aquila, M. E. A. 2006b. Potencial alelopático de espécies nativas na germinação e crescimento inicial de Lactuca sativa L. (Asteraceae). Acta Botanica Brasilica, 20 (1): 61-69.

Marenco, R. A.; Lopes, N. F. 2005. Fisiologia Vegetal: fotossíntese, respiração, relações hídricas e nutrição mineral. UFV: Viçosa, Brasil, 451pp.

Medeiros, A. R. M.; Lucchesi, A. A. 1993. Efeitos alelopáticos da ervilhaca (Vicia sativa L.) sobre a alface em testes de laboratório. Pesquisa Agropecuária Brasileira, 28 (1): 9-14.

Miró, C. P.; Ferreira, A. G.; Aquila, M. E. A. 1998. Alelopatia de frutos de erva-mate (Ilex paraguariensis) no desenvolvimento do milho. Pesquisa Agropecuária Brasileira, 33 (8): 261-270.

Periotto, F.; Perez, S. C. J. G. A.; Lima, M. I. S. 2004. Efeito alelopático de Andira humilis Mart. Ex Benth na germinação e no crescimento de Lactuca sativa L. e Raphanus sativus L. Acta Botanica Brasilica, 18 (3): 425-430.

Rice, E. L. 1984. Allelopathy. $2^{\text {th }}$ ed. Academic Press, New York, USA, 422pp.

Rodrigues, B. N; Passini, T.; Ferreira, A. G. 1999. Research on allelopathy in Brazil. In: Narwal, S. S. (Ed.). Allelopathy update. Science Publishers, New Hampshire, USA, p.307-323.

Salisbury, F. B.; Ross, C. 1992. Plant physiology. Wadsworth, Belmont, USA, 682pp.

Santana, D. G.; Ranal, M. A. 2004. Análise da germinação: um enfoque estatístico. UnB: Brasília, Brasil, 248pp.

Smith, A. E.; Martin, D. L. 1994. Allelopathic characteristics of three cool-season grass in the forage ecosystems. Agronomy Journal, 8 (2): 243-246.

Souza Filho, A. P. S.; Alves, S. M. 2002. Alelopatia princípios básicos e aspectos gerais. Embrapa Amazônia Oriental, Belém, Brasil, 260pp.

Teixeira, C. M.; Araújo, J. B. S.; Carvalho, G. J. 2004. Potencial alelopático de plantas de cobertura no controle de picão-preto (Bidens pilosa L.). Ciências e Agrotecnologia, 28 (3): 691-695.

Vieira, R. D.; Carvalho, N. M. 1994. Testes de vigor em sementes. Funep, Jaboticabal, Brasil 164pp.

Villela, F. A.; Doni Filho L.; Sequeira, E. L. 1991. Tabela de potencial osmótico em função da concentração de polietileno glicol 6.000 e da temperatura. Pesquisa Agropecuária Brasileira, 26 (11/12): 1957-1968.

Zhang, Q. 1993. Potential role of allelopathy in the soil and the decomposition root of chinese-fir replant woodland. Plant Soil, 151 (2): 205-209. 